\title{
1 GHz CMOS Band-pass Filter Design Using an Active Inductor and Capacitor
}

\author{
Siavash Heydarzadeh*, Pooya Torkzadeh \\ Department of Electrical Engineering, Science and Research Branch, Islamic Azad University, Tehran, Iran \\ *Corresponding author: S.heydarzadeh@srbiau.ac.ir
}

Received June 07, 2013; Revised June 27, 2013; Accepted June 30, 2013

\begin{abstract}
This work offers the use of an active inductor and capacitor to build RF band-pass filter with $0.18 \mu \mathrm{m}$ and TSMC process. Based on the proposed structure, a prototype $1 \mathrm{GHz}$ active filter designed and simulated in a $0.18 \mu \mathrm{m}$ CMOS technology. Simulation results for the designed RF band-pass filter show S21 > 19dB and consuming power less than $14 \mathrm{~mW}$ from $1.8 \mathrm{~V}$ supply voltage. The absolute values of reflection parameters (|S11| and |S22|) are about $60 \mathrm{~dB}$. Low-bandwidth linear noise at output node are less than $-170 \mathrm{~dB}$ and Advanced Design System (ADS) used to produce $1 \mathrm{GHz}$ band-pass active filter simulation results.
\end{abstract}

Keywords: active filter, active inductance, active capacitance, $0.18 \mu \mathrm{m}$ CMOS technology, ADS

\section{Introduction}

RF band-pass filters are used extensively in wireless communications. The challenge today is an alternative use of analog integrated active filtering to replace the combination of external passive filters and amplifiers [1]. The effort on integrating RF band-pass filters on a silicon substrate is accelerated with the emergence of monolithic spiral inductors and transformers. Even though there has been a great performance improvement of monolithic integrated inductors in CMOS process, the large areas occupied by the spiral inductors and the conductive substrate made passive inductors a reluctant choice to be employed in high-frequency circuit design where multiple inductors are required. The proposed active filter topology is based on the use of integrated inductors rather than offchip components to achieve important improvements in terms of cost and power consumption. A high degree of integration not only reduces the cost of the product by minimizing the number of off-chip elements, but also reduces power consumption by eliminating the need for driving typically low-impedance off-chip components [2]. The active inductor inherently occupies a very small chip area [3]. Active capacitor occupied less area as compared to electrolytic and polyester capacitors. In high frequency, using active capacitor decreased capacitive effect on the circuit and required low current to charge and discharge. For this reason the active capacitor circuit consumes low power as compared to the other topologies. Therefore, CMOS active inductors and capacitors have found increasing applications in RF band-pass filters. These band-pass filters possess several attractive characteristics, including high band-pass center frequency, large and tunable quality factor, low insertion loss and less power consumption. In This paper, a $1 \mathrm{GHz}$ band-pass active filter using an active inductor and capacitor is proposed.
The circuit has a low-power consumption, desired S parameters and low linear noise. Advanced Design System (ADS) and $0.18 \mu \mathrm{m}$ CMOS technology and TSMC process used to produce simulation results. The circuit is suitable for implement high order active filters in multistandard applications such as a wireless communication system.

\section{Active Inductor}

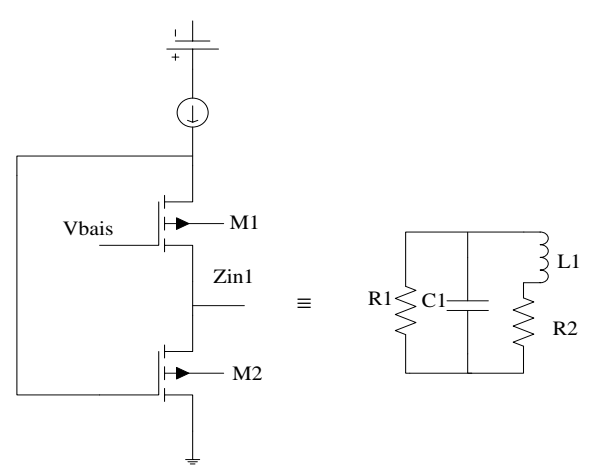

Figure 1. Active inductor with small-signal equivalent circuit

An active inductor in CMOS technology with a supply voltage of $1.8 \mathrm{~V}$ is presented. The value of the inductor (L), can be in the range from $0.5 \mathrm{nH}$ to $4 \mathrm{nH}$ in high frequency (HF). The proposed active inductor is simulated with $0.18 \mu \mathrm{m}$ CMOS technology and TSMC process. The power consumption of this inductor can retain constant at all operating frequency bands and consume around $5 \mathrm{~mW}$ from $1.8 \mathrm{~V}$ power supply. Figure 1 shows active inductor structure with small-signal equivalent circuit. The values of active inductor small-signal equivalent circuit parameters obtain from Eq. (1) to (4) [4].

$$
C 1=\text { Cgs1. }
$$




$$
\begin{gathered}
R 1=\frac{1}{g_{o 2}} \| \frac{1}{g_{m 1}} \approx \frac{1}{g_{m 1}} . \\
R 2 \approx \frac{g_{o 1}}{g_{m 1 \cdot g m 2}} .
\end{gathered}
$$

Table 1. Active Inductor Transistor's Dimensions.

\begin{tabular}{|c|c|c|c|c|c|c|}
\hline & $\mathrm{L}$ & $\mathrm{W}$ & $\mathrm{AD}$ & $\mathrm{AS}$ & $\mathrm{PD}$ & PS \\
\cline { 2 - 7 } & $(\mu \mathrm{m})$ & $(\mu \mathrm{m})$ & $(\mathrm{pm})$ & $(\mathrm{pm})$ & $(\mu \mathrm{m})$ & $(\mu \mathrm{m})$ \\
\hline M1 & 0.18 & 500 & 240 & 240 & 1001 & 1001 \\
\hline M2 & 0.18 & 90 & 43 & 43 & 181 & 181 \\
\hline M3-M4 & 0.25 & 600 & 288 & 288 & 1201 & 1201 \\
\hline
\end{tabular}

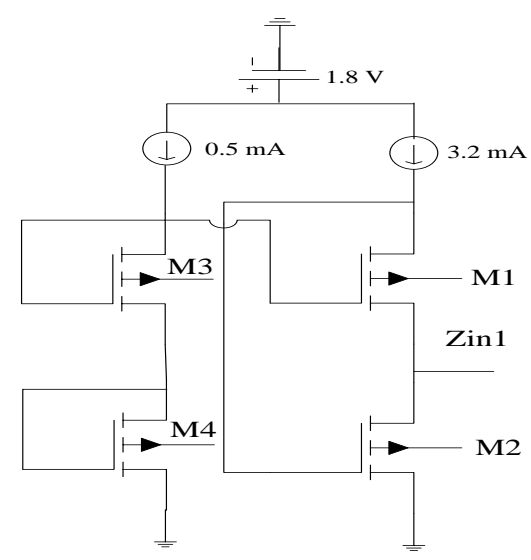

Figure 2. Active inductor with biasing circuit

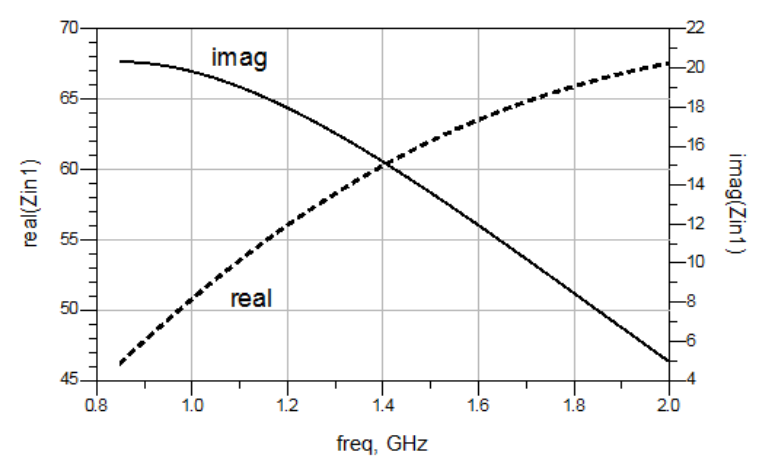

Figure 3. Real and imaginary part of active inductor input impedance

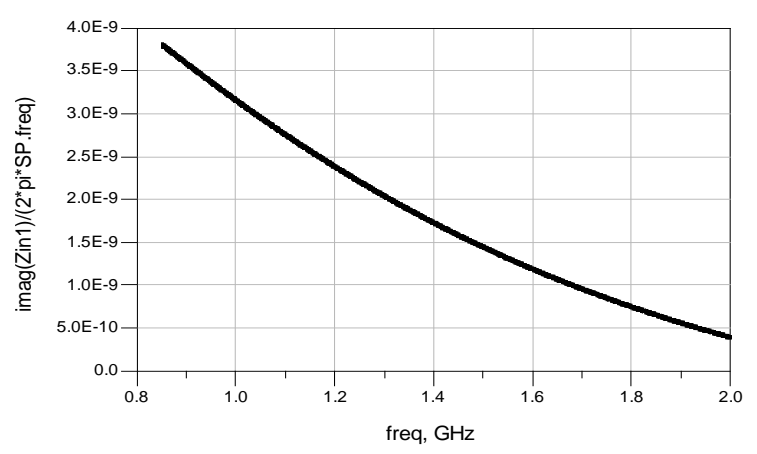

Figure 4. Inductance value (L)

$$
L 1=\frac{C g s 2+C g d 2+C g d 1}{g m 1 \cdot g m 2}
$$

Figure 2 displays complete active inductor circuit that created inductive part of filter. Table 1 presents transistor's dimensions, which used in the active inductor circuit. All transistors work in a saturation region. Figure 3 and Figure 4 display active inductor simulation results in a consider frequency.

\section{Active Capacitor}

Capacitive part of band-pass active filter created by CMOS active capacitor circuit, displayed in Figure 5. Active capacitor small-signal equivalent circuit is presented in Figure 6. Real and imaginary parts of input Impedance $(\mathrm{Rt}+1 / \mathrm{j} \omega \mathrm{Ct})$ obtain from Eq. (13) and (14). In small-signal equivalent circuit assumed that M1 and M2 were identical.

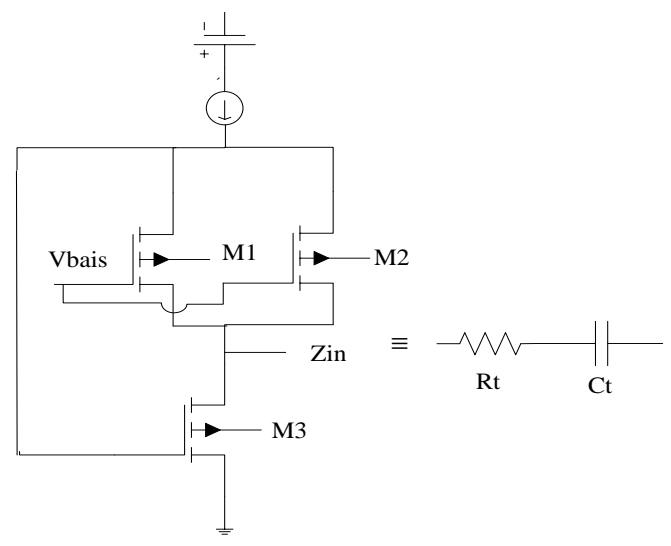

Figure 5. Active capacitor circuit

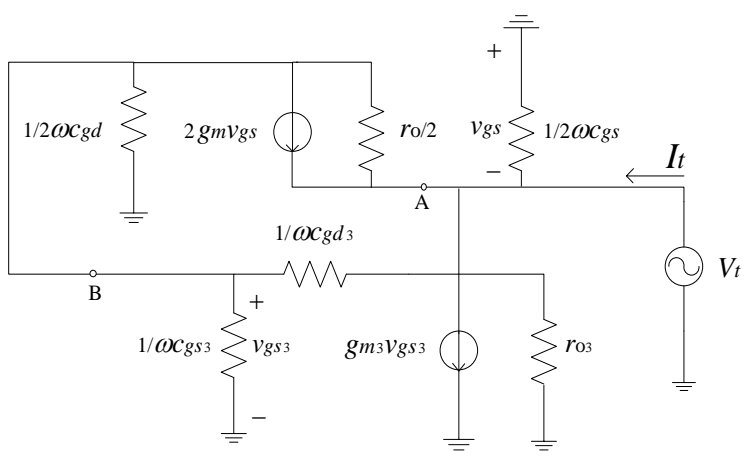

Figure 6. Active capacitor small-signal equivalent circuit

$\mathrm{M} 1 \equiv \mathrm{M} 2$ then:

$$
\begin{gathered}
g m 1=g m 2=g m . \\
C g s 1=C g s 2=C g s . \\
C g d 1=C g d 2=C g d . \\
r o 1=r o 2=r o .
\end{gathered}
$$

KCL in A:

Vt.go3 + gm3.vgs3 $+(V t-v g s 3) \cdot \omega \cdot C g d 3+V t .2 . \omega \cdot C g s+$ $(V t-v g s 3) \cdot 2 \cdot g o=2 . g m \cdot v g s+I t$.

$\mathrm{KCL}$ in B:

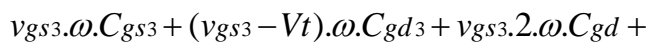

$$
\begin{aligned}
& \text { 2.gm.vgs }+(v g s 3-V t) \cdot 2 \cdot g_{o}=0 .
\end{aligned}
$$

KVL:

$$
V t=-v g s .
$$

Vt/It gets from Eq. (9) to (11).

$$
\frac{V t}{I t}=\operatorname{Zin}=R t+\frac{1}{j \omega C t} .
$$




$$
\begin{aligned}
& R t \approx \frac{2 . g o}{2 . g o 3 . g o+2 . g m 3 . g m+2 . g m 3 . g o} . \\
& C t=\frac{4 \cdot \operatorname{Cgs} \cdot \operatorname{Cgd}+2 \cdot \operatorname{Cgd} 3 \cdot \operatorname{Cgd}+\operatorname{Cgd} 3 \cdot \operatorname{Cgs} 3+2 \cdot \operatorname{Cgs} \cdot \operatorname{Cgs} 3+2 \cdot \operatorname{Cgs} \cdot \operatorname{Cgd} 3}{\operatorname{Cgs} 3+\operatorname{Cgd} 3+2 \cdot \operatorname{Cgd}} \text {. }
\end{aligned}
$$

Figure 7 shows active capacitor with biasing circuit. M1 and M2 work in a triode region. The resistive part of the active capacitor is decreased by M2. M4 biased M1 and M2 in a triode region. Active capacitor transistor's dimensions are presented in Table 2. Figure 8 and Figure 9 show active capacitor simulation results. Real part of the input impedance is related to the resistive effect of the active capacitor circuit. Equation (15) gives capacitance value (in Figure 9).

$$
C=\frac{1}{2 \times \pi \times f \times \mid \operatorname{Im}(\text { Zin }) \mid}
$$

Table 2. Active Capacitor Transistor's Dimensions.

\begin{tabular}{|c|c|c|c|c|c|c|}
\hline \multirow{2}{*}{} & $\mathrm{L}$ & $\mathrm{W}$ & $\mathrm{AD}$ & $\mathrm{AS}$ & $\mathrm{PD}$ & $\mathrm{PS}$ \\
\cline { 2 - 7 } & $(\mu \mathrm{m})$ & $(\mu \mathrm{m})$ & $(\mathrm{pm})$ & $(\mathrm{pm})$ & $(\mu \mathrm{m})$ & $(\mu \mathrm{m})$ \\
\hline M1-M2 & 0.18 & 100 & 48 & 48 & 201 & 201 \\
\hline M3 & 0.18 & 600 & 288 & 288 & 1201 & 1201 \\
\hline M4 & 2 & 100 & 48 & 48 & 201 & 201 \\
\hline
\end{tabular}

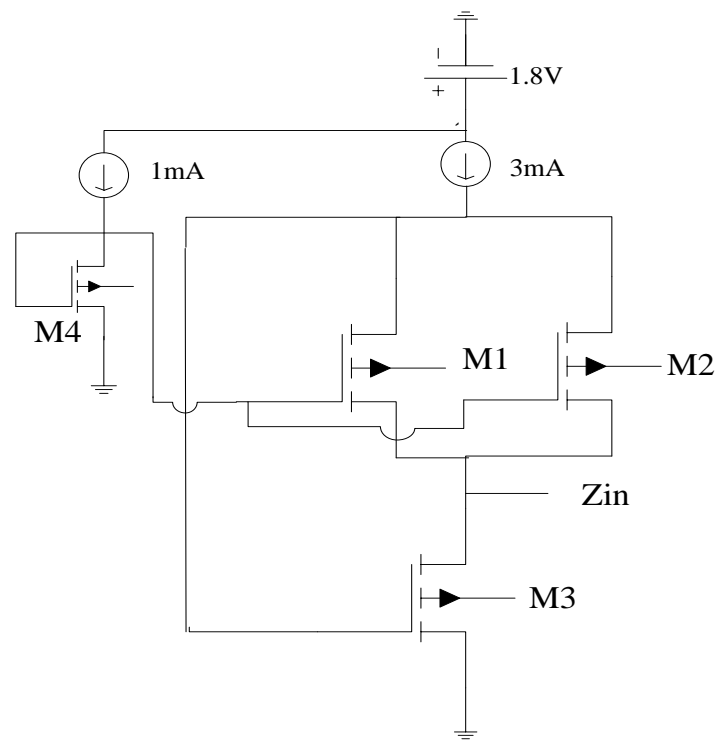

Figure 7. Active capacitor with biasing circuit

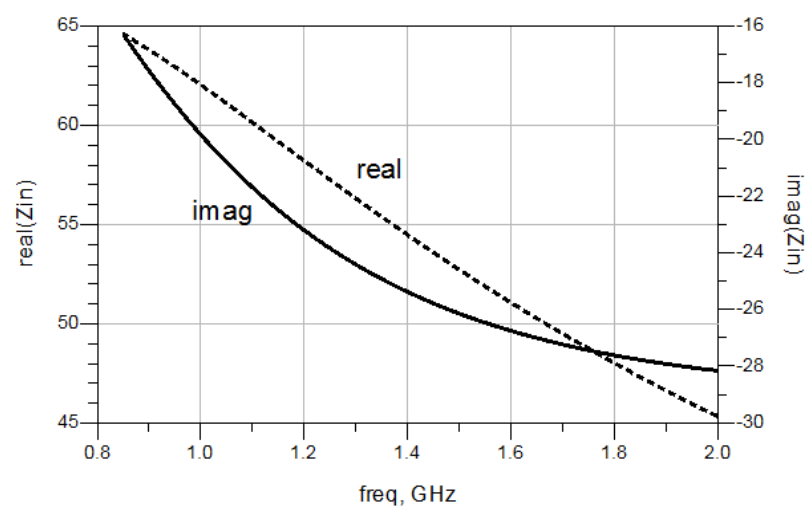

Figure 8. Real and imaginary part of active capacitor input impedance

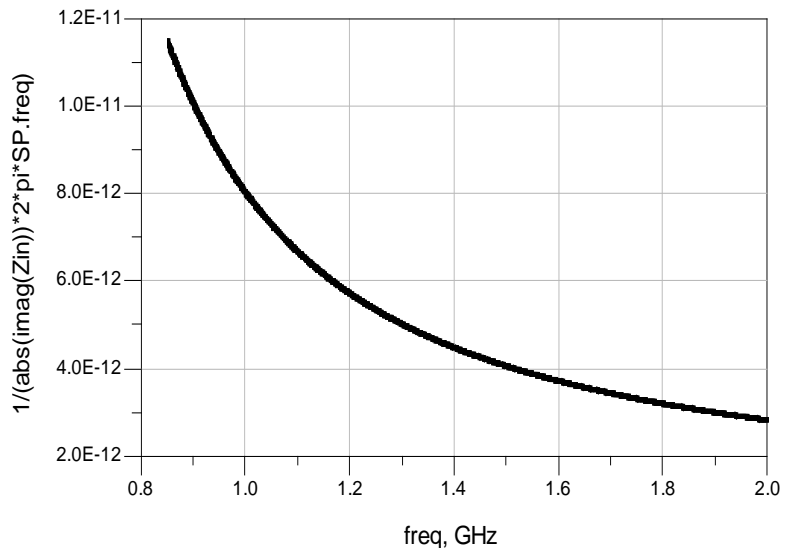

Figure 9. Capacitance value (C)

\section{Active Filter}

Active filter circuit based on the active inductor and capacitor is shown in Figure 10. Circuit specifications:

1- $1.8 \mathrm{~V}$ DC supply voltage.

$2-(0.5+3.2+1+3) \mathrm{mA} \times 1.8 \mathrm{~V} \cong 14 \mathrm{~mW}$ power consumption.

3- Sinusoidal input voltage.

4- Filter center frequency $(f c)$ described by Eq. (16). $\mathrm{L}=3.16 \mathrm{nH}$ in $1 \mathrm{GHz}$ (as Figure 4 shown) $\mathrm{C}=8 \mathrm{pF}$ in $1 \mathrm{GHZ}$ (as Figure 9 shown)

$$
f_{c}=\frac{1}{2 \pi \sqrt{L C}}=\frac{1}{2 \pi \sqrt{\left(3.16 \times 10^{-9}\right)\left(8 \times 10^{-12}\right)}} \cong 1 \mathrm{GHz} \text {. (16) }
$$

DC block capacitors in active filter circuit separate inductor and capacitor circuits. The values of DC block capacitors did not influence on active inductor and capacitor circuits. For example:

$$
\begin{gathered}
\frac{1}{C t}=\frac{1}{\text { Cactive }}+\frac{1}{C_{D C \_b l o c k}} . \\
\text { Cactive }<<\text { CDC_block. } \\
C_{t} \cong \text { Cactive. }
\end{gathered}
$$

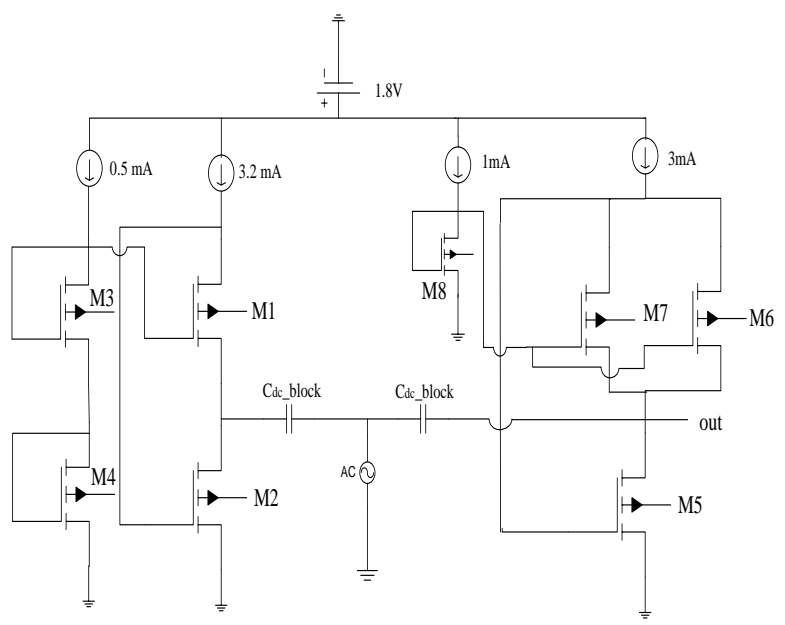

Figure 10. Active filter with biasing circuit

\section{Simulation Results}


With a $1.8 \mathrm{~V}$ supply voltage, the circuit consumes power less than $14 \mathrm{~mW}$. At center frequency, the S21 response of RF band-pass active filter is $19 \mathrm{~dB}$ as Figure 11 shown. Reflection parameters S11 and S22 are about $60 \mathrm{~dB}$ as Figure 12 and Figure 13 displayed.

Figure 14 and Figure 15 display Linear noise at the output node. Linear noise in the ADS consists of four parts (as ADS help mention):

1- Temperature-dependent thermal noise from lossy passive elements, including those specified by data files.

2- Temperature and bias-dependent noise from nonlinear devices.

3- Noise from linear active devices specified by 2-port data files that include noise parameters.

4- Noise from noise source elements.

Figure 14 shows the amplitude of linear noise with $1 \mathrm{~Hz}$, $5 \mathrm{~Hz}$ and $10 \mathrm{~Hz}$ bandwidth in considering frequency at the output node. Figure 15 displays linear noise with $100 \mathrm{~Hz}$, $500 \mathrm{~Hz}$ and $1 \mathrm{kHz}$ bandwidth at active filter operating frequency. Simulation results describe that the lowbandwidth linear noise amplitude at the output node in considering frequency are less than $-170 \mathrm{~dB}$. Table 3 presents simulation results briefly.

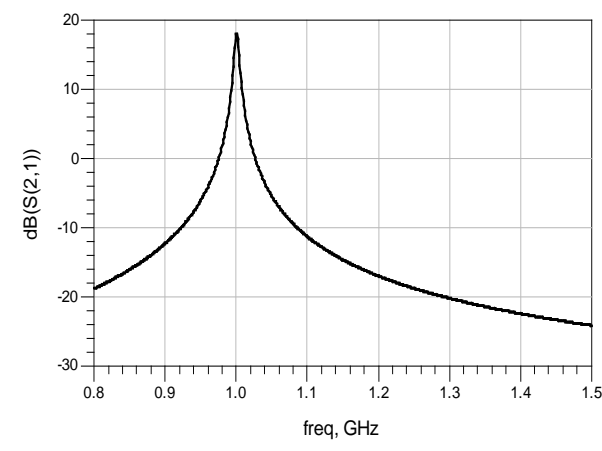

Figure 11. S21 response of RF band-pass filter

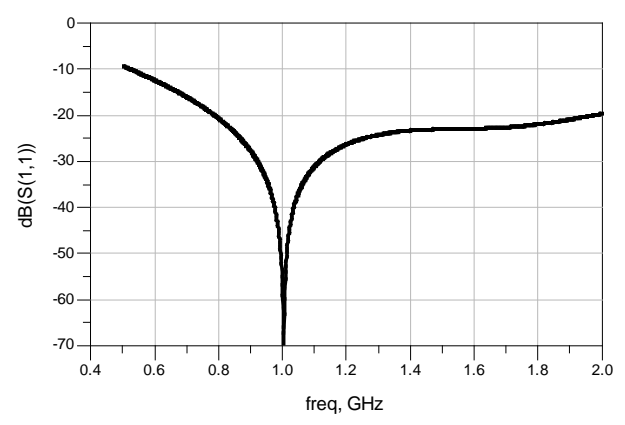

Figure 12. S11 reflection parameter

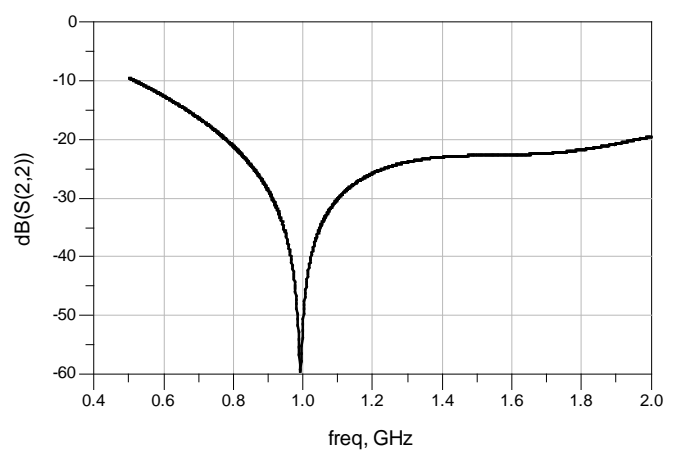

Figure 13. S22 reflection parameter

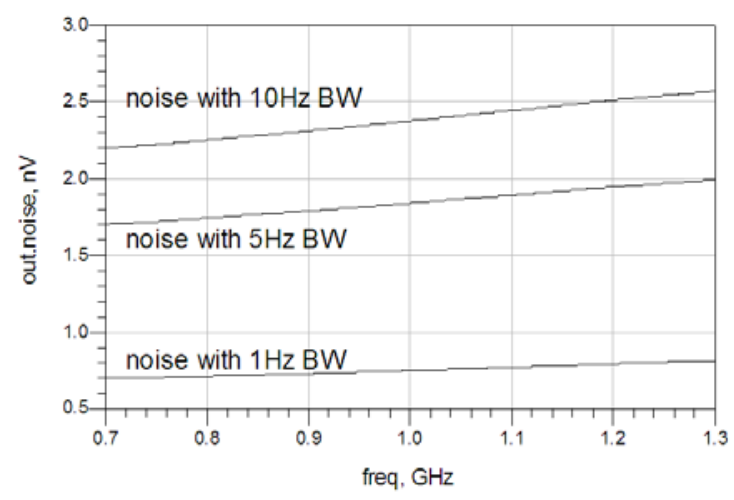

(a)

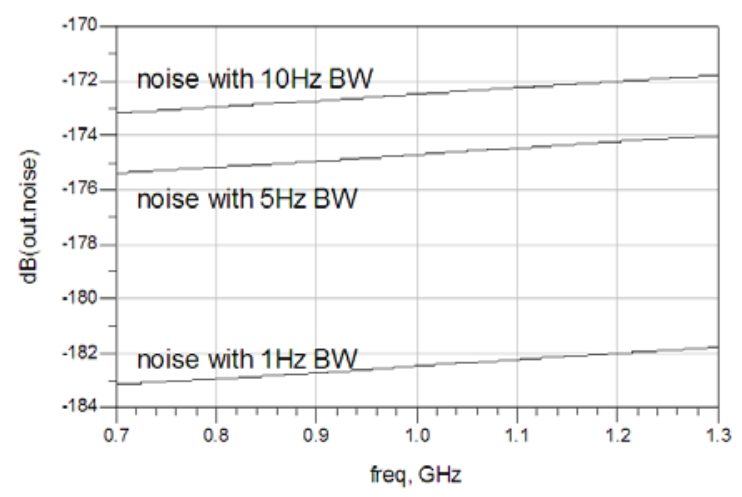

(b)

Figure 14. The amplitude of low-bandwidth linear noise at output node a)volt mode, b)dB mode

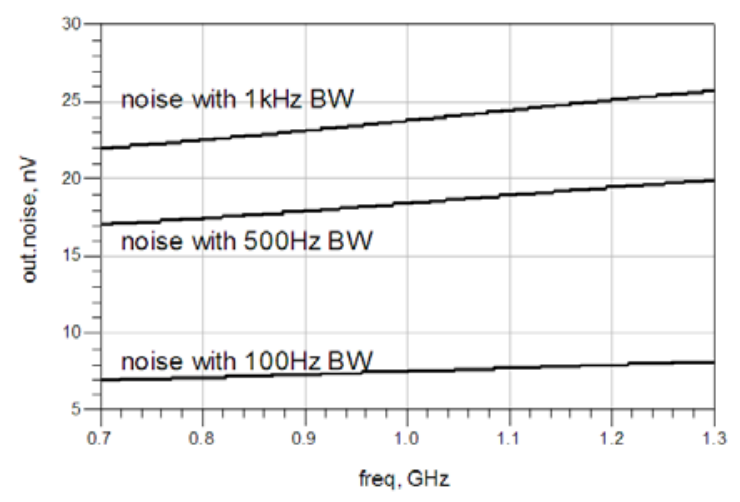

(a)

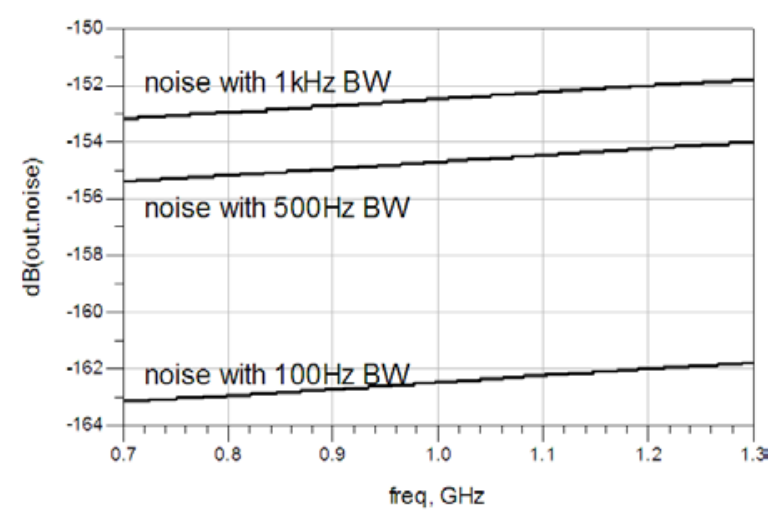

(b)

Figure 15. The amplitude of $100 \mathrm{~Hz}, 500 \mathrm{~Hz}$ and $1 \mathrm{kHz}$ bandwidth linear noise at output node a)volt mode, b)dB mode 
Table 3. Summary of Filter Specifications.

\begin{tabular}{|c|c|}
\hline Supply voltage & $1.8 \mathrm{~V}$ \\
\hline Current & $7.7 \mathrm{~mA}$ \\
\hline Power consumption & $14 \mathrm{~mW}$ \\
\hline Center frequency & $1 \mathrm{GHz}$ \\
\hline S21 (at center frequency) & $19 \mathrm{~dB}$ \\
\hline$|\mathrm{S} 11|$ & $-70 \mathrm{~dB}$ \\
\hline$|\mathrm{S} 22|$ & $-60 \mathrm{~dB}$ \\
\hline BW(-3dB) & $\approx 4 \mathrm{MHz}$ \\
\hline Low-bandwidth linear noise at output & $<50 \mathrm{nV}$ \\
\hline
\end{tabular}

\section{Conclusion}

Active filter based on the active inductor and capacitor is successfully designed and simulated with $0.18 \mu \mathrm{m}$ CMOS technology and TSMC process. The proposed band-pass active filter circuit has acceptable results from $0.5 \mathrm{GHz}$ to $2 \mathrm{GHz}$ frequency range. Active filter power consumption is less than $14 \mathrm{~mW}$ from $1.8 \mathrm{~V}$ supply voltage, which is very small as compared to other circuits using the same technology. At center frequency $(1 \mathrm{GHz})$ the $\mathrm{S} 21$ response of $\mathrm{RF}$ active filter is about $19 \mathrm{~dB}$ and the absolute values of reflection parameters ( $|\mathrm{S} 11|$ and $|\mathrm{S} 22|)$ are near $60 \mathrm{~dB}$. Low-bandwidth linear noise at output node are less than $-170 \mathrm{~dB}$ which desired for $\mathrm{RF}$ applications and not impact on circuit's performance. This on-chip active filter is suitable for wireless system applications such as channel selection, image rejection, etc.

\section{References}

[1] Z. Sassi, S. Darfeuille, B. Barelaud, L. Billonnet, B. Jarry, H. Marie, N. T. L. Le, P. Gamand, "2 GHz Tuneable Integrated Differential Active Bandpass Filter on Silicon,” GeMiC , 2005, PP. 90-93.
[2] K. Allidina, Sh. Mirabbasi, "A Widely Tunable Active RF Filter Topology,” ISCAS IEEE conference, 2006, PP. 879-882.

[3] D. Cordova, J. D. l. Cruz, C. Silva, "A 2.3-GHz CMOS High-Q Bandpass Filter Design Using an Active Inductor,” XV Workshop Iberchip, Buenos Aires, Argentina, 2009.

[4] M. Sabaghi, M. Rahnama, M. N. Lahiji, M. S. Miri, Sh. Rezakhani, "Design and Simulation of Differential Active Inductor with 0.18 $\mu \mathrm{m}$ CMOS Technology," Canadian Journal on Electrical and Electronics Engineering, vol. 2, no. 9, 2011.

[5] Z. Sassi, S. Darfeuille, B. Barelaud, L. Billonnet, B. Jarry, H. Marie, N. T. L. Le, P. Gamand, "2 GHz Tunable Integrated Differential Active Bandpass Filter on Silicon,” GeMiC, 2005.

[6] K. Allidina, Sh. Mirabbasi, "A Widely Tunable Active RF Filter Topology,” Department of Electrical and Computer Engineering University of British Columbia, ISCAS, 2006.

[7] Y. Koutsoyannopoulos, "Novel Si Integrated Inductor and Transformer Structures for RF IC Design,” IEEE International Symposium on Circuits and Systems, vol. 2, pp. 573-576, 1999.

[8] C. Andriesei, L. Goras, "On the Tuning Performance of an Active RF Bandpass Filter,” Acta Technica Napocensis Electronics and Telecommunications, 2008.

[9] G. Zhiqiang, "Design of CMOS Integrated Q-enhanced RF Filters for Multi-Band/Mode Wireless Applications,” Advanced Trends in Wireless Communications, 2005.

[10] Z. Xiong, "Radio Frequency Low Noise and High Q Integrated Filters in Digital CMOS Processes," A Thesis Presented to The Academic Faculty, Georgia Institute of Technology, 2004.

[11] C. E. Saavedra, W. Yang, "2GHz Bandstop Active Filter Using Operational Trans-conductance Amplifiers,” Department of Electrical and Computer Engineering Queen's University Kingston, Ontario, Canada, 2010.

[12] M. Ebrahimzadeh, “A Low Voltage High Quality Factor Floating Gate Tunable Active Inductor with Independent Inductance and Quality Factor Tuning,” International Journal of Computer and Electrical Engineering, vol. 3, no. 2, 2011.

[13] H. Xiao, "Recent Integrated Active Inductor Patents," Recent Patent on Electrical Engineering, 2009.

[14] A. V. Garcia, J. S. Martinez, E. S. Sinencio, "RF Bandpass Filter Design Using Capacitive Degeneration,” Analog and MixedSignal Center, Electrical Engineering Department, Texas A\&M University, College Station, Texas, USA, 2005. 